\title{
Huge Atypical Appendicitis in a 14-Year-Old Male: A Case Report
}

\author{
Ahmad Rezaee Azandaryani ${ }^{1}$, Mohamadmehdi Eftekharian$^{1}$, Mehdi Mousavi $^{2}$, Leili Ebrahimi $^{2 *}$ \\ ${ }^{1}$ Radiology Department, Hamedan University of Medical Sciences, Beasat Hospital, Hamedan, Iran \\ ${ }^{2}$ Cardiology Department, Alborz University of Medical Sciences, Shahid Rajaei Hospital, Karaj, Iran \\ Email: ahmad_rezaee20@yahoo.com,mehdief@gmail.com, Mmoosavi@razi.tums.ac.ir, ^lilieage@gmail.com
}

How to cite this paper: Azandaryani, A.R., Eftekharian, M., Mousavi, M. and Ebrahimi, L. (2016) Huge Atypical Appendicitis in a 14-Year-Old Male: A Case Report. Case Reports in Clinical Medicine, 5, 426-430. http://dx.doi.org/10.4236/crcm.2016.511059

Received: September 27, 2016

Accepted: October 31, 2016

Published: November 3, 2016

Copyright (c) 2016 by authors and Scientific Research Publishing Inc. This work is licensed under the Creative Commons Attribution International License (CC BY 4.0). http://creativecommons.org/licenses/by/4.0/

\begin{abstract}
Normal appendix is 4 to $5 \mathrm{~mm}$ in diameter and approximately $8 \mathrm{~cm}$ in length; although it may be up to $30 \mathrm{~cm}$ long. Appendicitis is the inflammation of the appendix and is the most common cause of acute abdominal pain. Right lower quadrant pain, nausea, vomiting and fever are common signs of appendicitis but $20 \%$ to $33 \%$ of patients with suspected appendicitis present with atypical features. Case presentation: we presented a 14-year-old boy with abdominal pain predominantly in hypogastric area and LLQ (Left Lower Quadrant) that after ultrasound and CT study a large appendix $22 \mathrm{~mm}$ in diameter and $17 \mathrm{~cm}$ in length was detected. Conclusion: appendix position and size is very variable and appendicitis could be presented by different clinical features. In this case, the patient was presented with LLQ pain rather than RLQ (Right Lower Quadrant) pain due to its large size and elongation to the left side.
\end{abstract}

\section{Keywords}

Huge Appendicitis, Ultrasonography, Noncompressible

\section{Introduction}

Appendix arises from posteromedial aspect of the caecum, 1 to $2 \mathrm{~cm}$ below the ileocecal valve.

Normal appendix is 4 to $5 \mathrm{~mm}$ in diameter and approximately $8 \mathrm{~cm}$ in length; although it may be up to $30 \mathrm{~cm}$ long.

Appendicitis is the inflammation of the appendix and is caused by a blockage of the hollow portion of the appendix, most commonly by a calcified particle called appendicolith, and is the most common cause of acute abdominal pain [1].

Right lower quadrant pain, nausea, vomiting, and a systemic inflammatory response 
with leukocytosis and neutrophilia, increased C-reactive protein concentration, and fever are considered diagnostic of appendicitis [2].

Approximately $20 \%$ to $33 \%$ of patients with suspected appendicitis present with atypical features. CT scan is now regarded as the most accurate test to diagnose appendicitis [3].

Appendiceal dilation greater than $13 \mathrm{~mm}$ suggests possible mucocele. Mocucele refers to distention of the appendix with sterile mucus. Some cases are due to mucinous cystadenoma or cystadenocarcinoma [1].

\section{Imaging Findings}

Non-compressible appendix larger than $6 \mathrm{~mm}$ in diameter in ultrasound study, visualization of the appedicolith (does not always indicate appendicitis), inflamed periappendiceal fat (echogen fat in sonography and fat stranding in CT scan), increased wall thickness and increased vascularity of the wall in color doppler sonography and wall enhancement in CT scan with contrast [1].

\section{Case Presentation}

A 14 years old boy presented with abdominal pain predominantly in hypogasteric area and LLQ, nausea and vomiting since 12 hour before admission.

WBC count was 12,000 with $80 \%$ neutrophils.

Abdominopelvic sonography was done for patient. Findings of ultrasound study was a large noncompressible tubular structure, $22 \mathrm{~mm}$ in diameter which was elongated from RLQ to LLQ, containing fluid and three ehogenic lesions inside the tubule; The largest was $14 \mathrm{~mm}$ (appendicolith) in length (Figure 1 and Figure 2). Small amounts of free fluid in pelvis and several lymph nodes in RLQ was also detected; with largest diameter of $5 \mathrm{~mm}$ in short axis.

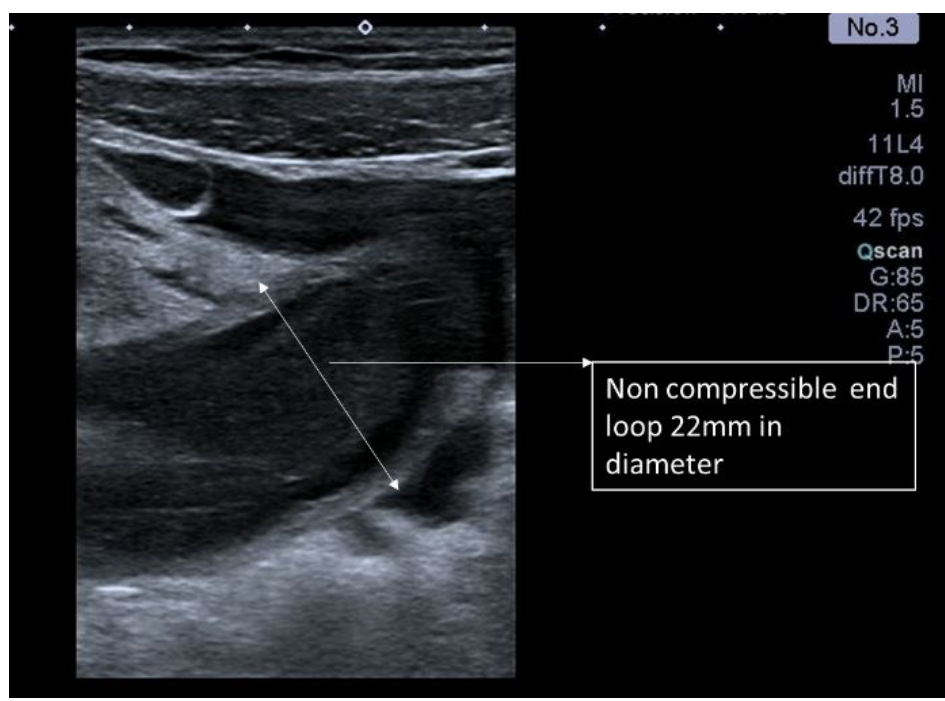

Figure 1. Ultrasound demonstrates tip of the non-compressible end loop in LLQ, which is $22 \mathrm{~mm}$ in diameter. 


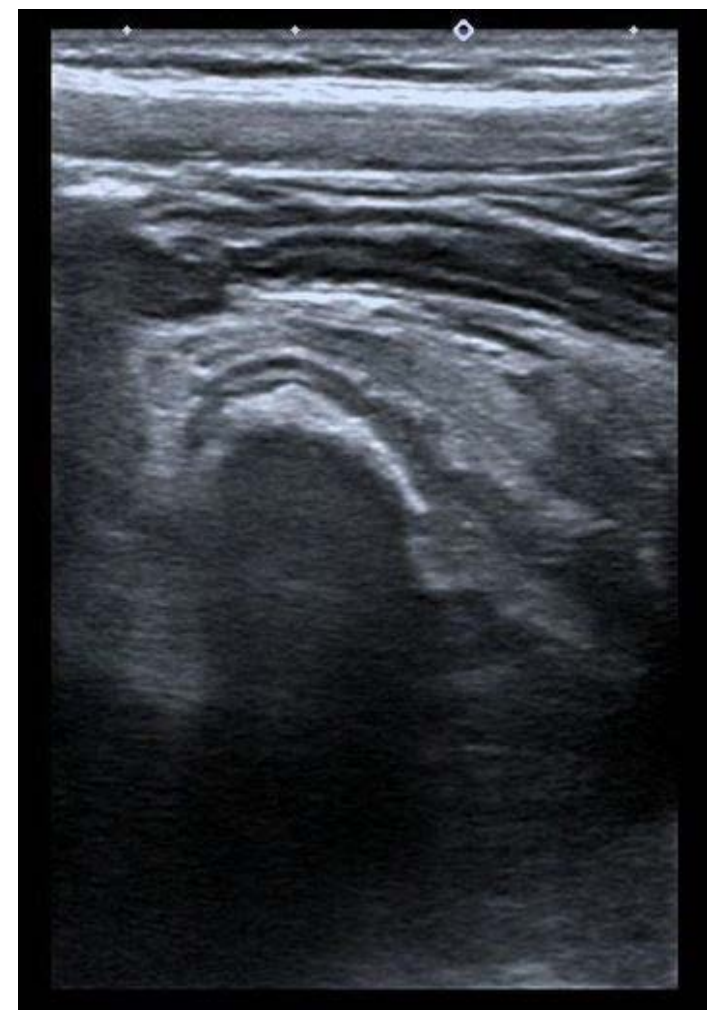

Figure 2. Another ultrasound image shows large appendicolith measured $14 \mathrm{~mm}$ in diameter.

In order to do more investigation, abdominopelvic CT scan with IV and oral contrast was requested. Findings were similar to those found in ultrasound, and also wall enhancement in tubular structure was detected (Figure 3(a) \& Figure 3(b)).

Regarding to ultrasound and findings of CT scan, acute appendicitis with possibility of mucocele formation was suggested.

Appendectomy for the patient was done and pathologic study confirmed the diagnosis of acute appendicitis but with no evidence of mucocele formation (Figure 4).

\section{Discussion}

Approximately $20 \%$ to $33 \%$ of patients with suspected appendicitis present with atypical features [3]. It can occur in both normal position appendix or in atypical positioned appendix.

The tip of the appendix can have a variable position within the abdominal cavity: retrocaecal $(65 \%-70 \%)$, pelvic $(25 \%-30 \%)$, pre- or post-ileal $(5 \%)$.

Duplication of the vermiform appendix is extremely rare with reported incidence of $0.004 \%$ patients operated on for acute appendicitis [4].

Left sided appendicitis is a rare pathology. Two situations may explain the occurrence of the disease: situs inversus or midgut malrotation [5].

Knowledge about these entities and their variations helps us diagnose atypical and problematic cases. 


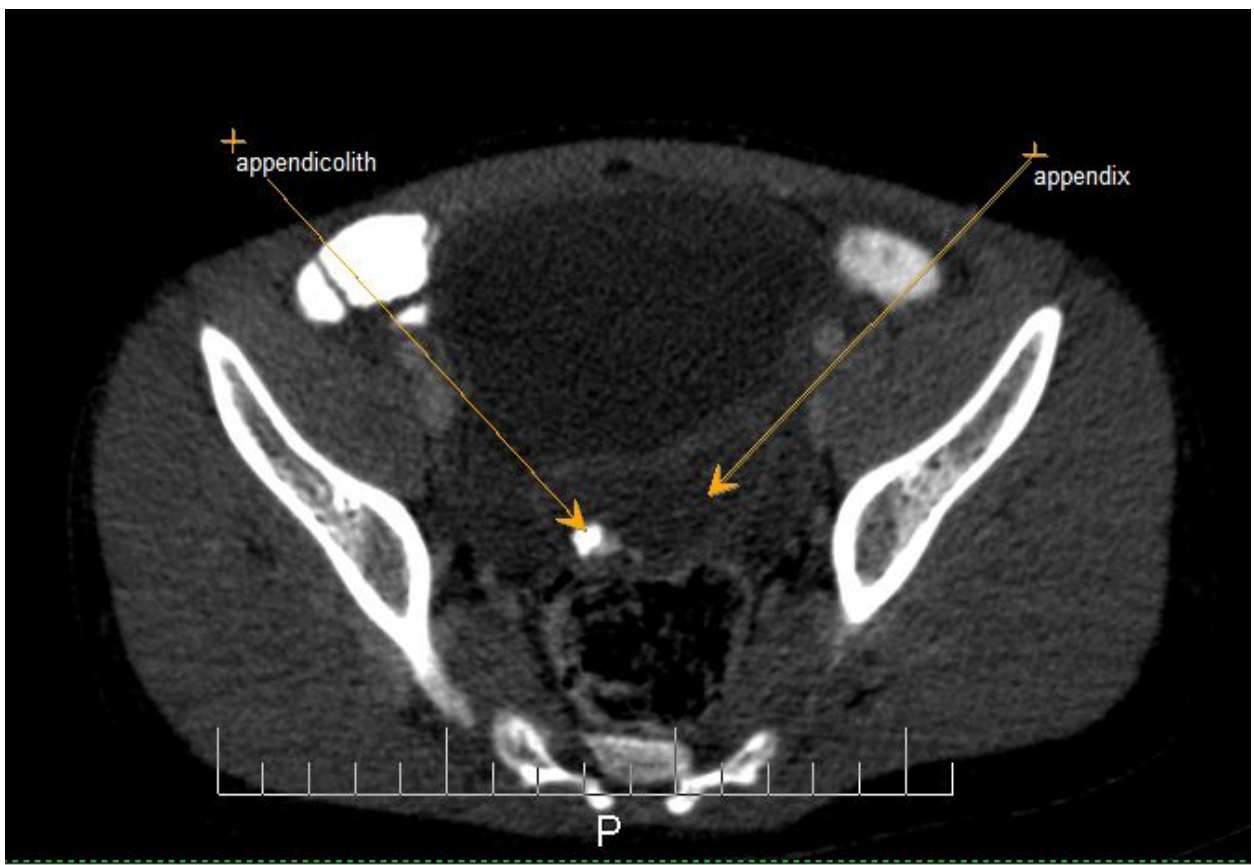

(a)

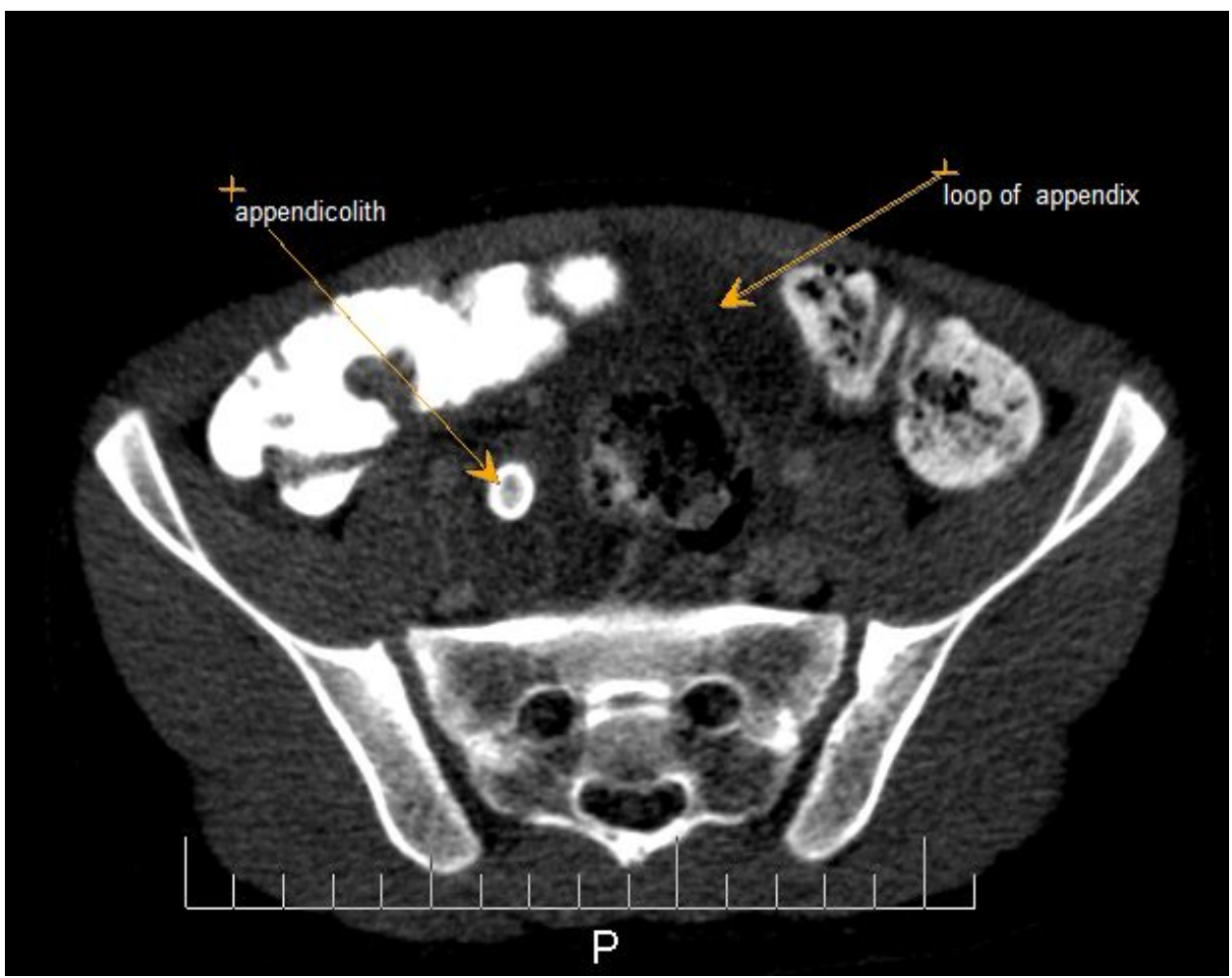

(b)

Figure 3. (a) Axial contrast enhanced CT scan demonestrates large appendix $22 \mathrm{~mm}$ in diameter with wall enhancement and an appendicolith; (b) Axial contrast enhanced CT scan at the level of sacroiliac joints demonestrates elongation of appedix to left side and another appendicolith, which is $14 \mathrm{~mm}$ in size. 


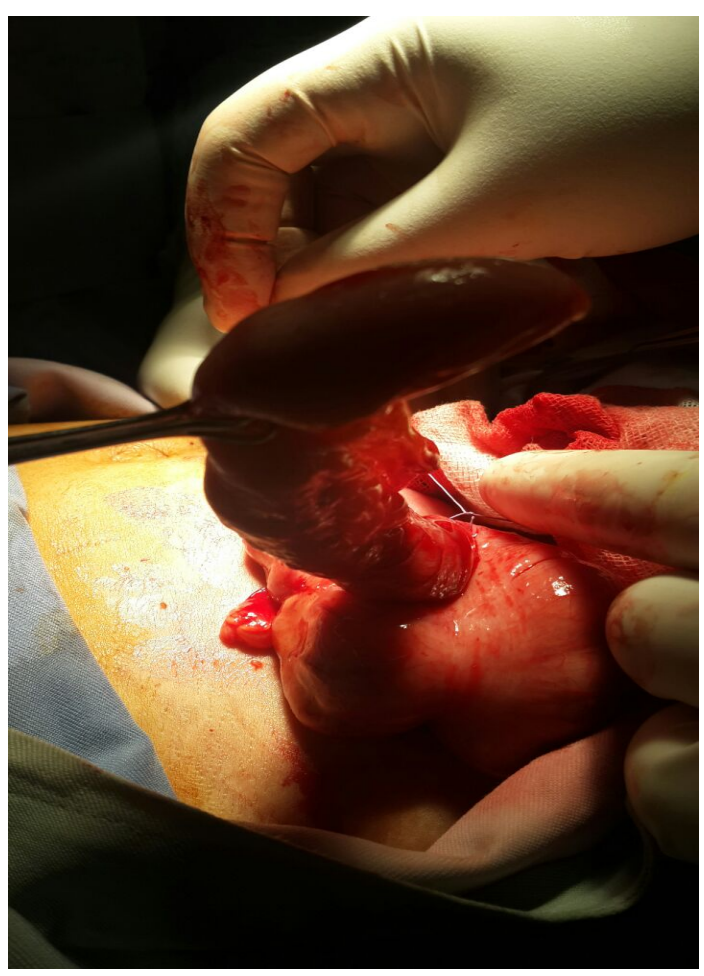

Figure 4. Intraoperative image shows huge appendix, measured $17 \mathrm{~cm}$ in length.

\section{Conclusions}

Most cases of appendicitis present with abdominal pain especially in RLQ. However, in some cases, that location of appendix is atypical (retrocecal, subhepatic, ...) or the appendix is elongated (such as this case presentation). So the clinical presentation can be different.

Appendicitis can be manifested by RUQ tenderness when location of appendix is subhepatic or LLQ tenderness when appendix is elongated and the tip of appendix is inflamed.

\section{References}

[1] Brant, W.E. and Helms, C.A. (2012) Fundamentals of Diagnostic Radiology. 4th Edition, Wolters Kluwer/Lippincott Williams \& Wilkins Health, Philadelphia, p. 792.

[2] Brunicardi, F.C., Andersen, D.K., Billiar, T.R., Dunn, D.L. and Hunter, J.G. (2014) Schwartz's Principles of Surgery. 10th Edition, McGraw-Hill Education, New York, p. 1241.

[3] Haaga, J.R., Dogra, V.S., Forsting, M., Gilkeson, R.C., Kwon Ha, H. and Sundaram, M. (2009) CT and MRI of the Whole Body. 5th Edition, Mosby, Philadelphia, p. 1349.

[4] Mushtaque, M., Mehraj, A., Khanday, S. and Dar, R. (2012) Double Appendicitis. International Journal of Clinical Medicine, 3, 60-61. http://dx.doi.org/10.4236/ijcm.2012.31013

[5] Sidibé, K., Ossibi, P., Traoré, Z., Kamaoui, I., Lamrani, Y., Boubbou, M., Maâroufi, M., Oudou, A., Laalim, S., Mazaz, K. and Tizniti, S. (2016) Left Sided Acute Appendicitis: Radiological Aspects. Open Journal of Radiology, 6, 96-99.

http://dx.doi.org/10.4236/ojrad.2016.62014 
Submit or recommend next manuscript to SCIRP and we will provide best service for you:

Accepting pre-submission inquiries through Email, Facebook, LinkedIn, Twitter, etc. A wide selection of journals (inclusive of 9 subjects, more than 200 journals)

Providing 24-hour high-quality service

User-friendly online submission system

Fair and swift peer-review system

Efficient typesetting and proofreading procedure

Display of the result of downloads and visits, as well as the number of cited articles

Maximum dissemination of your research work

Submit your manuscript at: http://papersubmission.scirp.org/

Or contact crcm@scirp.org 